\title{
AVALIAÇÃO: \\ REGULADORA OU EMANCIPATÓRIA?
}

\author{
Marília Claret Geraes Duran*
}

\section{Resumo}

Este artigo propõe-se a contribuir para a discussão a respeito do papel central que a avaliação vem desempenhando na formulação e na implementação de políticas educacionais, assumindo uma função estruturante nas reformas educativas conservadoras e neoliberais em curso em países centrais, como os Estados Unidos e a Inglaterra entre outros, e na transposição do modelo para a América Latina e para o Brasil. As constatações de estudo sobre a produção acadêmica sobre a avaliação da escola básica no Brasil, publicada em dez periódicos nacionais entre 1990 e 1998, são apresentadas na perspectiva de oferecer elementos de análise para compreender as funções de controle do estado sobre a escola pública e de introdução da lógica do mercado em avaliações de larga escala, problematizando as possibilidades e os limites de a avaliação vir a constituir-se numa prática política emancipatória.

Palavras-chave: Avaliação Educacional, Reformas educativas, Reformas neoliberais, Escola básica.

\section{Abstract}

This article leads to discussion about the central role that the educational assessment has fulfilled in the formulation and implementation of educational policies assuming a structural function in the conservative and neoliberal reforms taking place in central countries as the United States and England among others, and the transposing of model countries as the United States and England among others, and transposing of the model to Latin America and to Brazil. The findings in the study of the academic production in the assessment of elementary schools in Brazil, published in ten national newspapers between 1990 and 1998, are presented in the perspective of offering markers to analyze the functions of controlling by the state public schools, and the introduction of the market logic in the assessment of a large

Doutora em Psicologia da Educação pela PUC-SP. É Pesquisadora-Docente da Faculdade de Educação e Letras e Coordenadora do Programa de Pós-Graduação em Educação - Mestrado, da UMESP (Universidade Metodista de São Paulo).

E-mail: duran@mtecnetsp.com.br 
quantity of the students' production, dealing with the possibilities and limits of assessment become a political practice of emancipation.

Keywords: Educational Assessment, Educational Reforms, Neoliberal Reforms, Elementary School.

\section{Introdução}

Este artigo propõe-se a contribuir para a discussão a respeito do papel central que a avaliação vem desempenhando na formulação e na implementação de políticas educacionais, assumindo uma função estruturante nas reformas educativas conservadoras e neoliberais em curso em países centrais como os Estados Unidos e a Inglaterra, entre outros, e na transposição do modelo para a América Latina, como no caso do Brasil.

Num primeiro momento, procura destacar as constatações de estudo sobre a produção acadêmica acerca da avaliação da escola básica no Brasil, publicada em dez periódicos nacionais entre 1990 e 1998, Barretto e Pinto $(2000)^{1}$, especialmente 0 modelo de avaliação de larga escala, dentro do paradigma positivista que, na perspectiva da pesquisa, é entendida como a avaliação padronizada do rendimento escolar dos alunos, realizada no âmbito dos sistemas nacionais ou estaduais de avaliação do ensino básico - a chamada "avaliação de monitoramento".

A seguir, retomo as características dessa modalidade de avaliação, para compreender as suas funções de controle por parte do Estado e de introdução da lógica do mercado, problematizando as possibilidades e os limites de a avaliação vir a constituir-se numa prática política emancipatória.

\section{Consta tações de estudo sobre a produção aca dêmica acerca da avaliação de monitoramento}

\subsection{Pressupostos e inventário das fontes}

A avaliação de monitoramento ganhou força nos anos noventa, apoiada em estudos sobre desenvolvimento industrial, tecnologia e educação, cuja preocupação, conforme sinaliza Gusso (1992, p. 69), estava relacionada com o perfil educativo-cultural da força de trabalho, dos trabalhadores, dos novos paradigmas da organização da produção e do trabalho e que colocavam a questão da "qualidade" como o grande desafio para 0 sistema educativo-cultural do Brasil: mais do que o direito social de acesso à escola, o desafio era o de fazer a qualidade do cidadão, a qualidade do trabalhador, a qualidade do familiar, a qualidade do indivíduo. 0 
questionamento da escola básica brasileira, pelos mais variados segmento s da sociedade, dirigido à sua finalidade fundamental de garantir educação de qualidade à população, expressava a preocupação central com a produtividade do sistema. Nesse contexto, a questão que se colocava era "saber exatamente o que a escola está fazendo, qual o seu papel ideal e discutir o que é que efetivamente poderia estar fazendo" (p.70).

Avaliar processos e resultados do sistema educacional é, segundo Gusso, uma imposição que decorre desses questionamentos: quais são os padrões de qualidade possíveis? Como estabelecer a medida dessas possibilidades? Como aferir isso?

Com essas preocupações, o Instituto Nacional de Estudos e Pesquisas Educacionais do Ministério da Educação (INEP) se propôs a implantar um sistema permanente de avaliação que contribuísse, no dizer de Bessa (1992, p. 80), para melhorar a qualidade das escolas, integrando um sistema de aferição e avaliação do sistema instrucional, sistema esse conhecido como SAEB - Sistema Nacional de Avaliação da Educação Básica, e que, ao mesmo tempo, contribuísse para alterar tanto a prática pedagógica quanto as características gerais do sistema educacional.

O SAEB, conforme descrição feita por Pestana (1992, p. 81), foi concebido em dois níveis: o primeiro refere-se a indicadores de produtividade e de eficiência, com a aplicação de um modelo de fluxo e produtividade da UNESCO, que permite a análise do sistema educacional como um todo - taxas de produtividade, perdas com evasão e repetência, níveis de escolarização real em cada um dos estados e do país; o segundo nível proposto no sistema de avaliação refere-se às condições de trabalho e às condições da escola - questõ es relativas à gestão escolar, ao trabalho dos professores em sala de aula e ao seu próprio pensamento acerca do trabalho, às formas de organização e aos objetivos do trabalho docente, ao custo efetivo de cada aluno e ao rendimento escolar. A metodologia utilizada procura estudar as correlações entre questões relativas à gestão escolar, competência docente, custos e rendimento dos alunos. O rendimento dos alunos é o contraponto desse sistema.

Além dos estudos no âmbito da escola, o sistema de avaliação também propôs estudos na esfera de gestão do sistema educacional, gerando informações e propiciando uma base para tomada de decisões nas administrações educacionais. A proposta era a de que o SAEB não representasse um sistema fechado, mas uma base para que outros trabalhos de avaliação fossem agregados, ampliando a discussão sobre as condições e os fatores que afetam a educação no Brasil (PESTANA, 1992, p. 83).

Essas considerações iniciais traçam o cenário a partir do qual foi desenvolvido o inventário das fontes sobre Avaliação de Monitoramento: 
do total de artigos sobre Avaliação - cerca de duzentos e quarenta (240) em periódicos levantados, publicados de 1990 a 1998 - aproximadamente 28\% abordavam temas relacionados a esse tipo de avaliação.

Considerando-se os dez títulos de periódicos selecionados para 0 desenvolvimento da pesquisa ${ }^{2}$, observa-se que apenas cinco apresentaram artigos nesta categoria de análise, o que permite afirmar que o pensamento sobre o tema, disseminado no Brasil por meio desse tipo de publicação durante a década de 90, não apresenta uma distribuição eqüitativa, por não estar presente no conjunto de periódicos de circulação nacional. Na verdade, concentra-se num determinado título - a revista Estudos de Avaliação Educacional (EAE) -, que publicou $82 \%$ dos seus 67 textos. Nota-se, portanto, que 0 periódico Estudos em Avaliação Educacional, de responsabilidade da Fundação Carlos Chagas, caracteriza-se como uma revista identificada com esse tipo de avaliação e voltada para a disseminação de trabalhos relacionados ao estabelecimento de políticas que motivam a atitude avaliativa em relação ao sistema educacional.

\subsection{Conceituação e contex tua lização da ava lia ção de monitoramento}

A categorização e a análise dos artigos selecionados indicaram a predominância do discurso oficial nesta temática, tanto na sua explicitação como um sistema permanente de avaliação, quanto na discussão dos motivos que contribuíram para sua implantação como um sistema de aferição e avaliação do sistema educacional brasileiro, sistema esse conhecido como SAEB - Sistema Nacional de Avaliação da Educação Básica. Implantado, em âmbito nacional, pelo Ministério da Educação e do Desporto, a partir de 1990, o MEC/INEP vem realizando, periodicamente, a avaliação do desempenho escolar dos alunos e das condições pedagógicas e gerenciais da educação básica, gerando informações e propiciando, segundo a palavra dos gestores do ensino público brasileiro, uma base para a tomada de decisões nas administrações educacionais.

Comparando-se os estudos direcionados à conceituação de Avaliação de Monitoramento, não se podem identificar distinções marcantes entre eles, ao contrário, os pressupostos são claramente identificados com: a) medida da qualidade da educação - o que supõe estabelecer mecanismos que permitam objetivar e quantificar diversos produtos do processo educativo; $b$ ) bases para o desenho de instrumentos para medir qualidade educativa, com ênfase nos indicadores de qualidade: qualidade de produto, entendido como aprendizagem dos alunos e qualidade do processo de ensino, como medidas e 
acesso, fluxo escolar, características da escola e de investimentos financeiros com a educação; c) mensuração sistemática como meio de fornecer informações para o desenvolvimento de uma cultura avaliativa e para servir de base à monitoração do sistema educacional, com o objetivo de melhorar sua qualidade; d) gerenciamento do sistema de avaliação e sua implementação.

Pondo em destaque o caso brasileiro e as tentativas mais recentes de implantação de um sistema de avaliação no apoio à definição de políticas educacionais, os diversos autores apresentam algumas experiências de implantação de sistemas de avaliação na América Latina e nos Estados Unidos, na Inglaterra e no País de Gales, na Suécia e na França. Tais exemplos são utilizados no sentido de evidenciar a importância das informações que o serviço público deve dar à população, prestando contas dos serviços que oferece e dos recursos que lhe foram confiados (princípio da accountability), além de considerar esse tipo de avaliação importante para orientar as ações voltadas para o sistema de ensino no que diz respeito à formulação, implementação, manutenção e revisão de medidas educacionais. Os autores sinalizam as perspectivas que essas avaliações vêm abrindo em alguns países para a tomada de decisões capazes de romper as contradições, os conflitos e as incoerências que existem entre o discurso e a prática, entre a formulação e a execução de políticas educacionais.

Apresentando, pois, constatações que motivam a atitude avaliativa em relação ao sistema educacional, os autores destacam aspectos positivos do modelo, levantando questões de cunho teórico-metodológico sobre os quais a atenção dos pesquisadores tem convergido nos últimos anos.

Dois artigos que identificam e analisam alguns problemas do SAEB tratam de aspectos relacionados com o seu desenho, com sua aplicação, com sua agenda.

Oliveira (1995), por exemplo, em seu artigo publicado no periódico Em Aberto, discute o papel do MEC num país federativo, no qual a responsabilidade pelos sistemas de ensino compete aos estados e municípios, mas em que ele determina quais testes serão realizados, quando e como serão aplicados, quem serão os consultores, atribuindo-se a tarefa de elaborar os testes, aplicá-los e corrigi-los. $\mathrm{O}$ autor considera que, para aprimorar o sistema de avaliação nacional, seria importante identificar as funções de cada ator (SAEB, estados, entidades especializadas, universidades), criando um arcabouço institucional que permitisse ao SAEB assumir e manter a liderança no setor, formar recursos humanos em quantidade, qualidade e diversidade suficientes e engajar o país nas instituições internacionais de avaliação.

O outro artigo, de Maluf (EAE,1996), apresenta uma discussão do SAEB, considerando aspectos críticos identificados na sua implementação e desenvolvimento. A autora defende a necessidade de dados globais sistemati- 
zados, pelo fato de que os países latino-americanos não possuem esse tipo de informação. Mas também considera que a análise realizada nos diferentes sistemas implantados vem revelando dois tipos de obstáculos: a dificuldade em avançar ou aprofundar o exame dos resultados em função do tipo de instrumento utilizado e as dificuldades de estabelecer mecanismos de divulgação que garantam a assimilação e possibilitem a utilização efetiva da análise dos resultados pelas redes de ensino. Para ela, o desenho e os instrumentos do SAEB não estão adequados ao principal objetivo a que se propõe: melhorar a qualidade de ensino, porque o SAEB não tem permitido transformar os resultados em alternativas para intervenção.

O que não é explicitado nos diversos artigos e que, de fato, parece guiar a política educacional voltada para a educação básica é a progressiva implantação do modelo mercadológico, com a aplicação de testes para os alunos, com a publicação dos resultados do rendimento por escola, para efeito de orientação dos "consumidores" da mercadoria educacional. Isso começou a ser feito em Minas Gerais, na análise de Cunha, "segundo o figurino dos pedagogos do Banco Mundial, e se estende a todo o país pelo Sistema de Avaliação da Educação Básica - SAEB. Embora atue por amostragem, sua extensão a todas as escolas é uma possibilidade anunciada pelas propostas ..." (1996, p. 61).

Outro aspecto importante a ser considerado diz respeito à própria complexidade da questão da avaliação da qualidade da Educação. Demo (1990) evidencia as dificuldades de conceituar qualidade da educação e as possibilidades de medi-la, para efeitos de avaliação, introduzindo um novo complicador, que é o caso da qualidade política, distinguindo-a de qualidade formal.

Para ele, qualidade formal refere-se à competência de produzir e aplicar instrumentos, tecnologias, métodos, ciência; qualidade política refere-se à competência de projetar e analisar conteúdos histónicos (sociedades) pelo menos mais toleráveis (desejáveis). Na perspectiva de Demo, portanto, a separação (artificial) entre as faces formal e política é um problema difícil de ser resolvido, pois a competência formal não pode ser efetivada sem competência política e vice-versa.

\subsection{Os casos de São Paulo, Minas Gerais e Rio de Ja neiro}

Governos estaduais, como os de Minas Gerais, São Paulo e Rio de Janeiro, realizaram ou continuam realizando ações de avaliação do sistema educacional, tendo montado seus sistemas próprios de aferição de resultados. Trata-se, como já salientamos, de um tipo de avaliação ainda bastante incipiente no Brasil e, por isso mesmo, atrelado a experiências internacionais de implantação de sistemas de avaliação congêneres. 
Entretanto, é importante a constatação de que vários estudos antecederam a implantação do modelo nacional de avaliação - o SAEB. Focalizando aspectos de projetos/programas de avaliação, estudos pioneiros criaram certa competência em relação ao que se pode chamar de "avaliação de rendimento escolar nos sistemas de ensino" e, de certa forma, foram bem-sucedidos tanto do ponto de vista acadêmico da construção da própria pesquisa avaliativa e com algum impacto na consideração dos problemas educacionais, como por parte da administração pública, da comunidade geral de educadores ou por segmentos que tiveram acesso às informações e puderam subsidiar suas ações docentes e de gestão escolar.

Considerando o conjunto dos estudos mais sistemáticos desenvolvidos no Brasil - o Sistema de Avaliação do Rendimento Escolar do Estado de São Paulo (SARESP), o Programa de Avaliação da Escola Pública de Minas Gerais (PAEMG), o do Rio de Janeiro, além do próprio SAEB, observa-se que eles parecem encerrar-se em si mesmos, sem um esforço deliberado de articulação com os demais estudos realizados, não se evidenciando, portanto, reflexão acumulada a respeito. Os procedimentos metodológicos utilizados na implementação dos sistemas de monitoramento são diferenciados: os casos de São Paulo e do Rio de Janeiro iniciaram o processo com o auxílio de instituições especializadas para a montagem dos respectivos sistemas, enquanto em Minas Gerais a própria Secretaria assumiu o processo, com consultores externos. $\mathrm{O}$ desenvolvimento de capacidades avaliativas nas unidades gestoras do sistema educacional, regionalizando e integrando os diversos trabalhos realizados, é um objetivo proclamado, mas ainda não totalmente realizado, evidenciando a dificuldade de avançar ou aprofundar a análise sobre os resultados, além das dificuldades de estabelecer mecanismos de divulgação que garantam a assimilação das informações e possibilitem a utilização efetiva da análise dos resultados.

\subsection{Problematizando a avaliação de monitora mento}

O exame cuidadoso das avaliações de monitoramento (SAEB, SARESP, PAEMG, entre outros estudos chamados "pioneiros") revela, por um lado, a importância de o sistema gerar e processar informações e propiciar uma base para a tomada de decisões na implementação ou manutenção de políticas. Por outro lado, sinaliza para as limitações da aplicação de um modelo mercadológico com a utilização de testes e a publicação dos rendimentos dos alunos por escola para efeito de orientação dos 'consumidores' da mercadoria educacional.

Barretto (2000), discutindo o caso brasileiro, observa que: os aspec- 
tos concorrenciais característicos da lógica de mercado, podem ser mais facilmente atribuídos aos procedimentos ligados à avaliação de alunos dos cursos superiores, que vêm acompanhados da publicização dos resultados e estão fortemente associados a processos de autorização de funcionamento e ao credenciamento desses cursos. (p. 3)

No monitoramento dos sistemas de ensino básico, a ênfase está mais no papel compensatório do Estado, "na orientação das ações do Estado no sentido de suprir necessidades detectadas" (p. 3).

Contudo, alguns questionamentos emergem da sistematização dos estudos sobre o tema: qual o papel que a avaliação de monitoramento tem tido na tomada de decisões nas administrações educacionais? Qual o seu valor para gerar mudança educacional? Este tipo de avaliação está conseguindo viabilizar seu principal objetivo, ou seja, a mensuração sistemática do rendimento dos alunos como meio de fornecer informações para o desenvolvimento de uma cultura avaliativa tem contribuído para a monitoração do sistema educacional, melhorando sua qualidade? Ou seja, o seu desenho, os instrumentos utilizados têm permitido transformar os resultados do processo avaliativo em alternativas para intervenção?

Essas perguntas ainda permanecem sem respostas, evidenciando 0 silêncio quase total da literatura especializada, publicada nos periódicos analisados, com relação à identificação dessa dimensão suposta nos modelos de avaliação de monitoramento.

\section{Avaliação de monitoramento - características e funções}

Uma breve revisão das características e funções que a avaliação vem assumindo no contexto das mudanças econômicas e políticas mais amplas é fundamental para compreender as suas funções - de controle por parte do Estado e de introdução da lógica do mercado - e para problematizar as possibilidades e os limites de a avaliação vir a constituir-se numa prática política emancipatória.

A avaliação é, ela própria, uma atividade política. Como verificação da competência acadêmica, como promotora da competição entre alunos e escolas, para estabelecer a relação entre conteúdos e formas de avaliação, para a seleção e alocação diferenciada dos indivíduos s, "a escolha das modalidades e técnicas de avaliação dos alunos supõe e implica uma determinada orientação política" (AFONSO, 2000, p. 20).

As funções da avaliação mais referidas na literatura internacional "são as que dizem respeito à melhoria dos processos de aprendizagem; à seleção, certificação e responsabilização (accountability); à promoção da motivação 
dos sujeitos e ao desenvolvimento de uma consciência mais precisa sobre os processos sociais e educacionais e à função que relaciona a avaliação com 0 exercício da autoridade, sobretudo no contexto organizacional" (2000, p. 18), caracterizando-se aí sua dimensão política.

No caso da avaliação da educação básica no Brasil - o estudo sobre a produção acadêmica publicada em dez periódicos nacionais entre $1990 \mathrm{e}$ 1998 - , chama a atenção, na análise de Barretto (2000), "a presença majoritária de artigos que versam sobre idéias, conceitos, pressupostos, tendências da avaliação" (p. 1), predominando fundamentalmente dois modelos:

- um, o modelo de avaliação em larga escala, de tradição recente, ao qual já nos referimos, modelo esse ancorado no paradigma positivista e que vem desempenhando, como já sinalizado, papel estruturante das reformas educacionais em curso no país. Desse modelo de avaliação destacamos a avaliação de monitoramento, mas também são exemplos de aplicação de modelos e metodologias de avaliação em larga escala as que se utilizam de informações educacionais de censos demográficos, como os trabalhos de Ribeiro (1991), Klein e Ribeiro (1995), Fletcher e Castro (1993), para citar apenas os levantados no "estado da arte".

- outro, mais numeroso, o modelo que, a partir de diferentes vertentes teóricas, faz a crítica ao paradigma positivista e se dedica às questões do estatuto científico da avaliação da qualidade do ensino com ênfase nas variáveis do processo, mais do que no produto da avaliação, propondo que "a sua natureza deve ser eminentemente dialógica e dialética, voltada para a transformação, tanto no plano pessoal como no social" (BARRETTO, 2000, p. 5). Assim, na análise da autora, o eixo da avaliação desloca-se de uma preocupação técnica de medir o rendimento do aluno "e passa a centrar as atenções em torno das condições em que é oferecido o ensino, da formação do professor e de suas condições de trabalho, do currículo, da cultura e da organização da escola e da postura de seus dirigentes e demais agentes educacionais" (p. 5).

Entretanto, a avaliação é quase sempre um instrumento fundamental em termos de gestão, quando pensada do ponto de vista das organizações. Para além dos limites mais restritos do espaço pedagógico, "já existe um relativo consenso sobre a necessidade de melhor aparelhar os órgãos gestores dos sistemas escolares para uso de informações que subsidiem as políticas educacionais, bem como de promover a articulação entre as instâncias produtoras de conhecimento e aquelas encarregadas de oferecer o ensino básico" (BARRETTO, p. 4). 
Algumas das suas funções ganham maior destaque em determinados períodos históricos, sendo particularmente importantes em conjunturas socioeconômicas específicas, como é o caso do papel fundamental que a avaliação adquire nos países que têm procurado criar um "mercado educacional", de responsabilização pelos resultados escolares dos alunos, assumindo sua função nitidamente reguladora.

Afonso, com base nos estudos de Debora Willis (1992), analisa três modelos de responsabilização: a) o modelo de responsabilização baseado na lógica do mercado, dentro dos pressupostos da democracia liberal, em que a principal função da escola é a de proporcionar oportunidades para que cada indivíduo desenvolva suas capacidades inatas e contribua, com seu esforço, para o aperfeiçoamento da sociedade; b) o modelo gestionário-burocrático de responsabilização, em que a educação é vista como mercadoria, numa visão positivista da educação escolar e preocupada com resultados mensuráveis e c) o modelo de responsabilização profissional, em que a educação é percebida como um bem público, tendo nos professores os profissionais capazes de conduzir a uma melhoria da qualidade do ensino, valorizando modalidades de avaliação formativas e interpretativas (AFONSO, 2000, p. 45).

Considerando os modelos apresentados, como caracterizar a "avaliação de monitoramento" (SAEB, SARESP, PAEMG)? Poderíamos incluí-la dentro do modelo gestionário-burocrático de responsabilização, pois favorece o controle das escolas, utilizando-se de formas de avaliação predominantemente quantitativas (testes objetivos, estandardizados) que facilitam a medição e permitem a comparação de resultados acadêmicos? Embora não tenha na publicitação e difusão dos resultados uma condição essencial, tendendo mais para um controle interno, circunscrito ao sistema educativo e às escolas, do que para um controle externo e aberto às solicitações do mercado, o seu modelo atende também

aos processos de responsabilização ou de prestação de contas relacionados com os resultados educacionais e acadêmicos, passando estes a ser mais importantes que os processos pedagógicos (que teriam implicado outras formas de avaliação) (AFONSO, 2000, p. 120, Grifos do autor) ${ }^{5}$

Apesar das críticas alimentadas pela literatura acadêmica a respeito das possibilidades e limites da avaliação estandardizada (normativa ou criterial, com divulgação dos resultados), parece ser este o modelo prevalente na implementação das políticas educacionais nos anos noventa - uma avaliação que valoriza uma abordagem quantitativa, e que é utilizada como fator de mercado, como mecanismo de controle por parte do Estado avaliador ${ }^{6} \mathrm{e}$ fortemente identificada com as tendências de centralização curricular. 
Acrescente-se, ainda, o que disse Barretto (2000) a respeito do "crivo político que qualifica ou desqualifica certa natureza de estudos e de dados", o que significa que não há uma relação de linearidade, como pressupõe o modelo da racionalidade técnica, entre a "utilização plena da informação sistematizada nos moldes propostos e a tomada de decisões no âmbito dos complexos sistemas de ensino". Deixando de considerar "as condições sociais, culturais e políticas que envolvem conflitos de interesses, consensos e dissensos na formulação e gestão das políticas na área", tal modelo também parece ignorar "as enormes resistências geradas dentro dos próprios aparatos públicos sobre a divulgação de muitas informações colhidas por essa via, visto que elas podem ser consideradas como ameaças aos mecanismos de legitimação necessários à manutenção das posições de poder" (p. 4).

Já no modelo de responsabilização profissional, são valorizadas as modalidades formativas ou interpretativas de avaliação, com pressupostos incompatíveis ou contraditórios em relação aos dois modelos anteriores, e que valoriza a responsabilização pública que respeite a autonomia profissional dos professores. São defendidos os princípios da auto-avaliação por Elliott, (1982) e do controle da qualidade do ensino exercido pelos colegas no seio da equipe pedagógica (PERRENOUD, apud AFONSO , 2000, P. 48)7 ${ }^{7}$. Contudo, Bernstein (1990) lamenta que as preocupações com a educação democrática sejam substituídas por outras, de responsabilização pelos resultados escolares dos alunos, pois, para ele, ao "prestar contas", a eficiência e a avaliação farão muito pouco para promover uma educação democrática, mas muito farão para colocar as escolas dentro da economia de mercado e sua base ideológica, convicção com a qual partilhamos. (AFONSO, p. 48).

\section{Conclusão}

As discussões precedentes nos ajudam a entender as relações complexas e contraditórias presentes na avaliação de monitoramento e suas relações com as políticas educativas de cunho neoliberal e neoconservador, confirmando seu dispositivo de regulação e controle por parte do Estado.

Algumas questões emergem neste contexto: 0 que o Estado espera fazer enquanto prática política? O Estado depende dos resultados da avaliação de monitoramento para diagnosticar que a educação pública precisa de uma educação comprometida com as camadas mais pobres da população, uma educação comprometida com a transformação social? E o que significa uma escola ficar bem classificada nesta avaliação? Pode significar uma escola mais competente? Qual o sentido de competência? É competente uma escola que desenvolve um trabalho vinculado aos critérios estabelecidos pelo Estado? 
Ou, a escola é competente porque desenvolve um trabalho que resulta na inclusão e permanência dos seus alunos?

Como diz Afonso (2000),

A nova configuração das políticas educativas ... dão prioridade ao mercado, ... e em nome de valores como o individualismo possessivo, a competição, a discriminação social e a avaliação meritocrática e seletiva, tem promovido 0 abandono das preocupações do Estado providência com a igualdade de oportunidades e com a construção da escola democrática. (p. 130).

A avaliação, em sua função reguladora, de controle do Estado, parece vincular-se à idéia de desestimular uma avaliação na sua função emancipadora e vice-versa. Contudo, a despeito das "resistências" e dos "preconceitos", e até de uma "certa inércia" que determina várias dificuldades na disseminação de programas mais persistentes e mais abrangentes de avaliação educacional, para Barreto (2000, p. 10) "são os resultados apresentados pelos alunos que se prestam à validação social das funções exercidas pela escola", o que não significa dizer que tais resultados devem se prender exclusivamente a uma racionalidade científico-instrumental.

Deste princípio mais geral - promover um reequilíbrio entre regulação e emancipação - e tendo em vista os pressupostos teórico-metodológicos e políticos "inconciliáveis" nos quais estão assentados ambos os modelos, a avaliação formativa pode cumprir um papel fundamental como prática política, deslocando o eixo do produto para o processo e considerando alguns dos seus desdobramentos, ou seja:

- ir além das práticas de avaliação típicas de uma racionalidade científico-instrumental e superar as insatisfações com "a insuficiência de meios para ensaiar novas práticas avaliativas na direção chamada emancipatória" (BARRETOa, 2000, p. 9);

- ir além da visão que recusa comodamente a avaliação em larga escala, pelo seu caráter conservador, que podem estar favorecendo práticas conformistas e não reflexivas, "derivadas das incertezas e ansiedades que a introdução do modelo nas redes escolares vem causando" (BARRETO, 2000, p. 9);

- e dar um salto qualitativo na avaliação da educação básica, uma mudança efetiva no sentido de superar o caráter redutor e conservador da avaliação de monitoramento e, sem perder suas contribuições, chegar a uma avaliação emancipadora e inclusiva. 


\section{Notas}

1 A pesquisa sobre o Estado da arte - avaliação da educação básica - foi executada pela FCC, com financiamento Inep/PNUD (1999/2000) e dela participei como documentarista e uma das pesquisadoras, na organização e análise da categoria "Avaliação de Monitoramento".

2 Dentre os periódicos de maior expressão nacional na área, foram selecionados, para o estudo, por conterem artigos que abordam expressamente a questão da avaliação da escola básica, os seguintes: Cadernos de Pesquisa (CP); Educação \& Realidade (ER); Educação e Sociedade (ES); Em aberto (EA); Ensaio (EN); Estudos de Avaliação Educacional (EAE); Idéias (ID); Revista Brasileira de Estudos Pedagógicos (RBEP); Revista da Faculdade de Educação da USP (RFEUSP) e Tecnologia Educacional (TE).

3 Funções da avaliação escolar segundo Broadfoot: competence, competition, content, control. Citado por Afonso, 2000, p. 18.

4 Sobre o assunto, ler o BARRETO E. S. de S. et al. Estado da Arte: avaliação na educação básica, conforme bibliografia.

5 Grifo do autor.

6 O interesse demonstrado pela avaliação, especialmente por parte de govemos neoconservadores e neoliberais, começou a ser traduzido pela expressão "Estado avaliador" (cf. Neave, 1988; Henkel, 1991; O’Buachalla, 1992; Hartley, 1993).

7 Cf. Afonso, opus cit., p. 48.

\section{Referências}

AFONSO, A. J. Avaliação educacional: regulação e emancipação: para uma sociologia das políticas avaliativas contemporâneas. São Paulo: Cortez, 2000.

ANTUNES, A. L et al. Avaliação do rendimento do aluno da escola estadual de Minas Gerais: o CBA. Estudos em Avaliação Educacional, São Paulo, n. 6, p. 29-42, jul./dez. 1992.

ANTUNES, A. L \& SOUZA, M. A. de. A escola e a comunidade escolar na avaliação da escola pública de Minas Gerais. Idéias, São Paulo, n. 30, p. 21-38, 1998.

BARRETO E. S. de S. et al. Estado da arte: avaliação na educação básica.. São Paulo: FCC/ Inep/ Comped/ PNUD, 2000. Relatónio de pesquisa DE Fevereiro.

. A avaliação na educação básica: entre dois modelos. Disponível em: htpp://www.anped.org.br/. Acesso em: 04 jun. 2002.

BESSA, N. M. Comentários sobre a proposta da OREAL/Unesco para medição da qualidade em educação. Estudos em Avaliação Educacional, São Paulo, n. 2, p. 91-98, jul./dez. 1990.

CUNHA, L A. Os parâmetros curriculares para o ensino fundamental: convívio social e ética. Cadernos de Pesquisa, São Paulo, n. 99, p. 60-72, nov. 1996. 
DEMO, P. Qualidade da educação: tentativa de definir conceitos e critérios de avaliação. Estudos em Avaliação Educacional, São Paulo, n. 2, p. 11-26, jul./ dez. 1990.

DURAN, M. C. G. Categonia de análise: monitoramento. In: BARRETO E. S. de S. etal. Estado da arte: avaliação na educação básica. São Paulo: FCC/ Inep/ Comped/ PNUD, 2000. Relatónio de pesquisa Fevereiro de 2000.

. Avaliação de monitoramento: uma das categorias de análise do estado da arte: avaliação da educação básica. In: REUNIÃO ANUAL DA ANPED, 22., Anais Eletrônicos. Disponível em: http://www.anped.org.br/ . Acesso em: 02 out. 2002.

- Avaliação de monitoramento e gestão do sistema público de ensino. In: CONGRESSO LUSO-BRASILEIRO: POĹTICA E ADMINISTRAÇÃO DA EDUCAÇÃO: INVESTIGAÇÃO, FORMAÇÃO E PRÁTICAS, AVALIAÇÃO, CURRÍCULO E ORGANIZAÇÃO APEDAGÓGICA, 2., Anais... Braga, 2001. Braga: Universidade do Minho, 2001.

GOULART, I. B. O ciclo básico de alfabetização: lições de uma avaliação. Estudos em Avaliação Educacional, São Paulo, n. 6, p. 3-8, jul./dez. 1992.

GUSSO, D. A. Medida e avaliação educacional: problemas e tendências. Estudos em Avaliação Educacional, São Paulo, n. 6, p. 9-28, jul./dez. 1992.

MALUF, M. M. B. Sistema nacional de avaliação da educação básica no Brasil: análise e proposições. Estudos em Avaliação Educacional, São Paulo, n. 14, p. 5-38, jul./dez. 1996.

OLIVEIRA, J. B. A. E. O futuro do SAEB e a consolidação de políticas públicas. Em Aberto, Brasília: INEP, v. 15, n. 66, p. 3-11, abr./jun. 1995.

OLIVEIRA, D. P. T. de. Avaliação extema do ciclo básico: diagnóstico necessário à melhoria da qualidade da educação. Ensaio: Avaliação de Políticas em Educação. Rio de Janeiro, v. 6, n. 18, p. 67-84, jan./mar. 1998.

PESTANA, M. I. de S. O sistema nacional de avaliação da educação básica. Estudos em Avaliação Educacional, São Paulo, n. 5, p. 81-84, jan./jun. 1992.

VIANNA, H. M. Avaliação do ciclo básico de alfabetização em Minas Gerais. Estudos em Avaliação Educacional, São Paulo, n. 5, p. 91-94, jan./jun. 1992.

WAISSELFISZ, J. O sistema nacional de avaliação do ensino público de $1^{0}$ grau. Estudos em Avaliação Educacional, São Paulo, n. 4, p. 65-72, jul./dez. 1991. 